\title{
Characterization and acid resistance test of one-part geopolymer from fly ash and water treatment sludge
}

\author{
Aileen Orbecido ${ }^{1}$, Vuong Ho ${ }^{1}$, Hirofumi Hinode ${ }^{2}$, Winarto Kurniawan ${ }^{2}$, Long Nguyen ${ }^{1}$, and Michael Angelo \\ Promentilla ${ }^{1}$ \\ ${ }^{1}$ Chemical Engineering Department, Gokongwei College of Engineering, De La Salle University, Manila, Philippines \\ ${ }^{2}$ Department of Transdisciplinary Science and Engineering, Tokyo Institute of Technology, Tokyo, Japan \\ ${ }^{3}$ Chemical Engineering Department, Ho Chi Minh University of Technology, Ho Chi Minh City, Vietnam.
}

\begin{abstract}
Development of geopolymers from wastes or by-products introduces a sustainable approach to replace ordinary Portland cement (OPC)-based concrete with an eco-material of lower green-house gases emissions. However, safety concerns related to the conventional twopart geopolymer has limited large-scale applications of the product. In this context, a novel onepart geopolymer from coal fly ash and water treatment sludge has been presented. The transformation of raw materials to geopolymer was observed by FTIR, SEM and XRD analyses. Acid resistance test has proved that the new binder had great durability against sulphuric acid attack. After 28 days immersion in $5 \% \mathrm{H}_{2} \mathrm{SO}_{4}$ solution, weight of all samples was hardly changed. Compressive strength, on the other hand, has not decreased but significantly increased as curing time increased. The properties were also compared to those of control samples cured in water. It was demonstrated that strong acid immersion did not create any noticeable effect on the weight and strength of one-part geopolymer system developed from coal fly ash and water treatment sludge.
\end{abstract}

\section{Introduction}

Since the first attempt of Davidovits to create geopolymer in 1972, numerous efforts have been dedicated to develop an advanced material for wide range of applications [1]. In construction field, geopolymer studies aim in gradually replacing Ordinary Portland Cement (OPC) and can be attributed to its superior strength and low greenhouse gas emission [2,3]. Conventionally, aqueous alkali solution is used to dissolve aluminate and silicate species from starting materials so as to form a three-dimensional network [1]. To avoid the usage of corrosive and viscous alkali solution, recent researches has explored the feasibility of one-part geopolymer using solid activators [4].

In this study, coal fly ash (FA) and water treatment sludge (WTS) were used as raw materials for the production of one-part geopolymer. WTS is the residue from water treatment process that consist significant fraction of precipitated alum. The FA and WTS mixtures were activated by sodium hydroxide and sodium aluminate. The durability of the formed- geopolymer against acid attack is investigated in this study.

\section{Materials and Method}

\subsection{Materials}

The coal FA was obtained from a power plant in Luzon, Philippines. It was used without any pre-treatment. The wet WTS was collected from a water treatment plant in Manila, Philippines. The wet sludge was dried at $105{ }^{\circ} \mathrm{C}$ then ground using LA abrasion machine for 10,000 cycles. Anhydrous sodium hydroxide $(99 \% \mathrm{NaOH}$, Mega Source Scientific Supplies, Philippines) purchased from a local supplier in the Philippines and anhydrous sodium aluminate $\left(50-56 \% \mathrm{Al}_{2} \mathrm{O}_{3} ; 40-45 \% \mathrm{Na}_{2} \mathrm{O}\right)$ from Sigma-Aldrich were used as activators. Concentrated sulphuric acid (96.7\%) was purchased locally and diluted to $5 \%$ concentration for the acid resistance test.

\subsection{Geopolymer synthesis}

Anhydrous sodium hydroxide $(99 \% \mathrm{NaOH})$ was used as solid activator form fly ash based one-part geopolymer. Two sources of aluminates were examined including ground WTS and sodium aluminate $\left(50-56 \% \mathrm{Al}_{2} \mathrm{O}_{3} ; 40\right.$ - 
Table 1. Compositions of two geopolymer mixtures.

\begin{tabular}{ccc}
\hline $\begin{array}{c}\text { Component } \\
(\%)\end{array}$ & GP1 & GP2 \\
\hline FA & 72.7 & 93 \\
WTS & 22.3 & 0 \\
$\begin{array}{c}\text { Sodium } \\
\text { aluminate }\end{array}$ & 0 & 2 \\
$\mathrm{NaOH}$ & 5 & 5 \\
\hline
\end{tabular}

$45 \% \mathrm{Na}_{2} \mathrm{O}$, Sigma-Aldrich). Proportion of each mixture GP1 and GP2 is presented in Table 1. Water is added to each mixture and stirred by mechanical mixer for 10 minutes to obtain homogeneous pastes.

The paste was poured into $50 \times 50 \times 50 \mathrm{~mm}$ moulds. Steel moulds were greased beforehand in order to be demoulded easier. The samples were hardened for 7 days at ambient temperature and pressure. They were then removed from cubic moulds and kept at room temperature for another 14 days.

\subsection{Compressive strength test}

Unconfined compressive strength test was conducted in accordance with ASTM C109 standard [6].

Dimensions of specimens were firstly measured. Then, 50-mm cubes were placed on the holder put in specimen chamber of the Compression and Flexural Testing Machine in STRC, De La Salle University. Both surfaces exposed to the force were polished to avoid high deviation during the testing process. The loading speed was fixed at $0.35 \mathrm{kPa} / \mathrm{s}$. A computer was connected with the testing machine to record the result. Average of three replicates of each run was calculated.

\subsection{Sulphuric acid resistance test}

Following the curing period, samples GP1 and G2 were subjected to acid resistance test conforming to modified ASTM C267 standard [7].

Deterioration of specimens before and after acidic attack indicated acid resistance. It was determined by measuring the changes of compressive strength and weight. Three (3) days prior to acid immersion, samples were all submerged in water [8]. After that, weight and compressive strength of each sample were taken as initial values.

The samples were then immersed in 5\% sulphuric acid solution $[9,10]$. The solution to specimen volume ratio was kept constant at four throughout the test [8]. Weight and compressive strength were recorded after 7 and 28 days of immersion.

\subsection{Microstructure characterization}

Chemical composition of precursors was recorded by Energy-dispersive X-ray fluorescence (XRF) using S2 Puma machine in the Center of Viet Nam - German Technology. Morphology of structures was observed by a JEOL 5310 Tungsten Scanning Electron Microscope (SEM). The ground samples were put on the flatting metal circle pellet noted with number (from 1 to 4 ). The pellet was coated with a thin gold layer. Structural bonds were tested by Nicolet 6700 Fourier Transform Infrared Spectroscopy (FTIR) Spectrometer. Samples were ground and mixed with $\mathrm{KBr}$ powder. Then, the mixture was pressed into circle tablet in the circle steel mould. The outputs were recorded and saved in a computer connect with the system.

\section{Results and discussion}

\subsection{Characterization of raw materials}

Table 2 shows the elemental composition of FA and WTS in form of oxides as determined by XRF analysis. Both sludge and fly ash compose of high proportions of $\mathrm{Si}$ and Al., The percentages of $\mathrm{SiO}_{2}$ and $\mathrm{Al}_{2} \mathrm{O}_{3}$ in raw materials are similar with the range of these materials from various sources of WTS (Waijarean et al., 2014; Suksiripattanapong et al., 2015; Huang and Wang 2013) and FA (Blissett and Rowson, 2012). Specifically, WTS

Table 2. Elemental compositions of FA and WTS using XRF analysis.

\begin{tabular}{ccc}
\hline \multirow{2}{*}{$\begin{array}{c}\text { Element as } \\
\text { oxide form }\end{array}$} & \multicolumn{2}{c}{ Composition (wt.\%) } \\
\cline { 2 - 3 } & WTS & FA \\
\hline $\mathrm{SiO}_{2}$ & 42.0 & 33.9 \\
$\mathrm{Fe}_{2} \mathrm{O}_{3}$ & 19.3 & 26.5 \\
$\mathrm{Al}_{2} \mathrm{O}_{3}$ & 30.0 & 13.5 \\
$\mathrm{CaO}$ & 2.46 & 13.6 \\
$\mathrm{TiO}_{2}$ & 1.38 & 1.01 \\
$\mathrm{~K}_{2} \mathrm{O}$ & 0.784 & 1.19 \\
$\mathrm{MgO}$ & 1.45 & 7.92 \\
$\mathrm{SO}_{3}$ & 0.425 & 0.864 \\
$\mathrm{Na}_{2} \mathrm{O}$ & 0.196 & 0.357 \\
$\mathrm{Other}$ & 2.005 & 1.159 \\
\hline
\end{tabular}

is a rich source of $\mathrm{Al}\left(30 \% \quad \mathrm{Al}_{2} \mathrm{O}_{3}\right)$, thus it is a prospective precursor for zeolithic formation. Also, $\mathrm{CaO}$ content in FA is relatively high so that it can create a strong alkaline media for geopolymerization.

The microscale images of raw materials in Figue 1 show that FA consists of typical microspheres from 1 to $20 \mu \mathrm{m}$ [11], meanwhile, sludge does not contain any sphere but flaky phases.

Micrographs at magnification x200 imply that FA generally are small size. Whereas WTS contains larger grains probably due to hydroxyl groups of $\mathrm{Al}(\mathrm{OH})_{3}$ presented in non-calcined sludge [12]. 
FTIR spectra of starting materials are presented in Figure 2. The bands at around $1000-1100 \mathrm{~cm}^{-1}$ are assigned to $\mathrm{T}-\mathrm{O}-\mathrm{Si}$ asymmetric stretching vibration that identifies the presence of polysialates of aluminum network. The existence of bands at around $1630 \mathrm{~cm}^{-1}$ and $3420 \mathrm{~cm}^{-1}$ in both WTS and FA spectra are due to H-O$\mathrm{H}$ bending vibration of aluminosilicates. Especially, WTS has an additional peak at wavenumber $914 \mathrm{~cm}^{-1}$ indicating symmetric Al-O-Si stretching vibration of kaolin. A peak at $537 \mathrm{~cm}^{-1}$ implies the Si-O-Al bending vibration; however, this peak might be overlapped with absorption band of hematite mineral [13].

\subsection{Effect of water treatment sludge on fly ash based one-part geopolymer matrices}

The compressive strength values of both combinations sastify the strength requirement of nonloadbearing masonry unit which is $4.14 \mathrm{MPa}$ according to ASTM C129 [14].
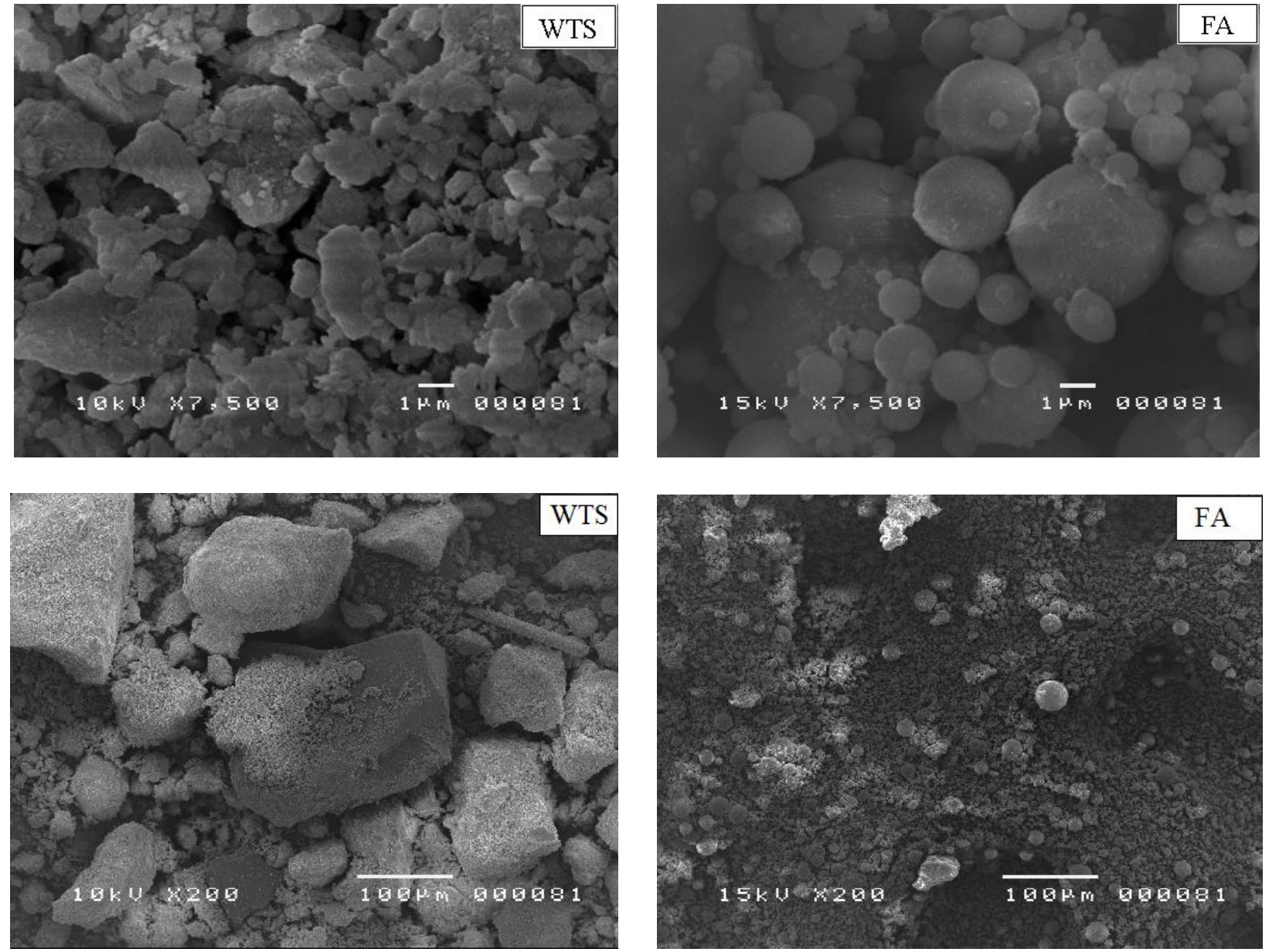

Fig. 1. SEM images of WTS and FA at magnifications of x7500 and x200
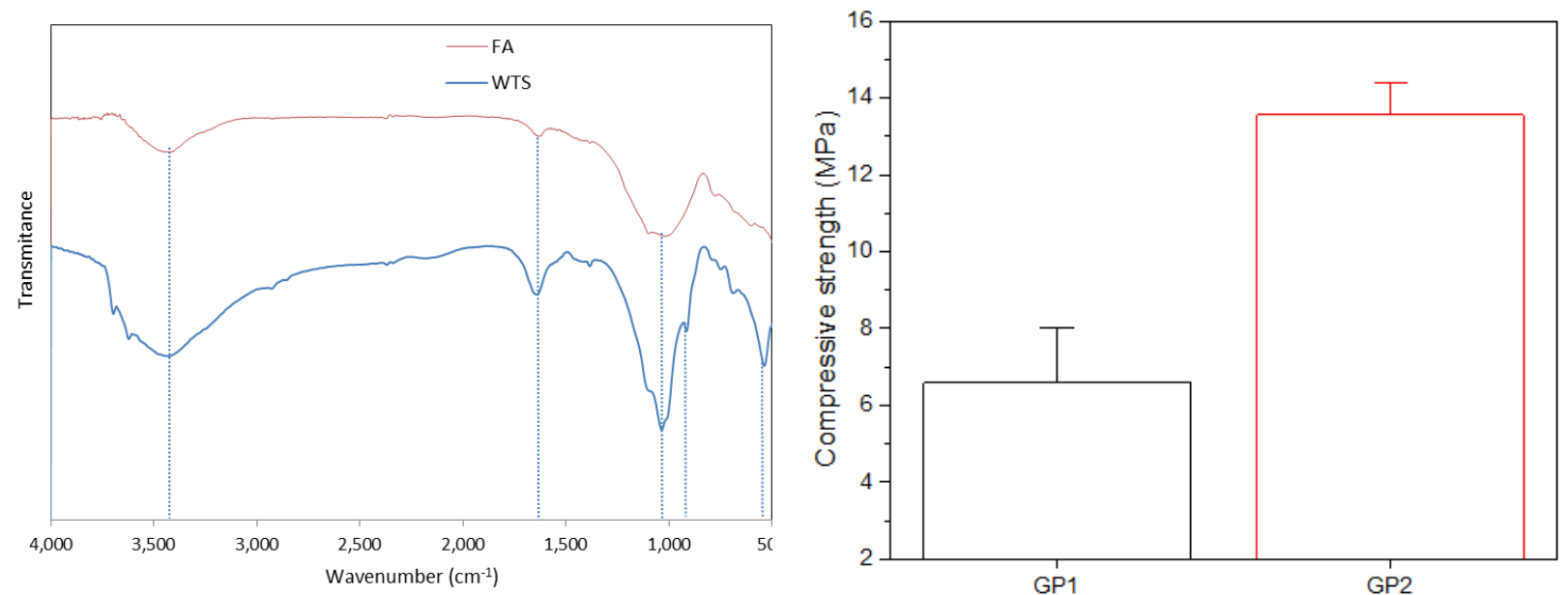

Fig. 2. SEM images of geopolymers GP1 and GP2

Fig. 3. Compressive strength values of GP1 and GP2, the bars represent standard deviations 

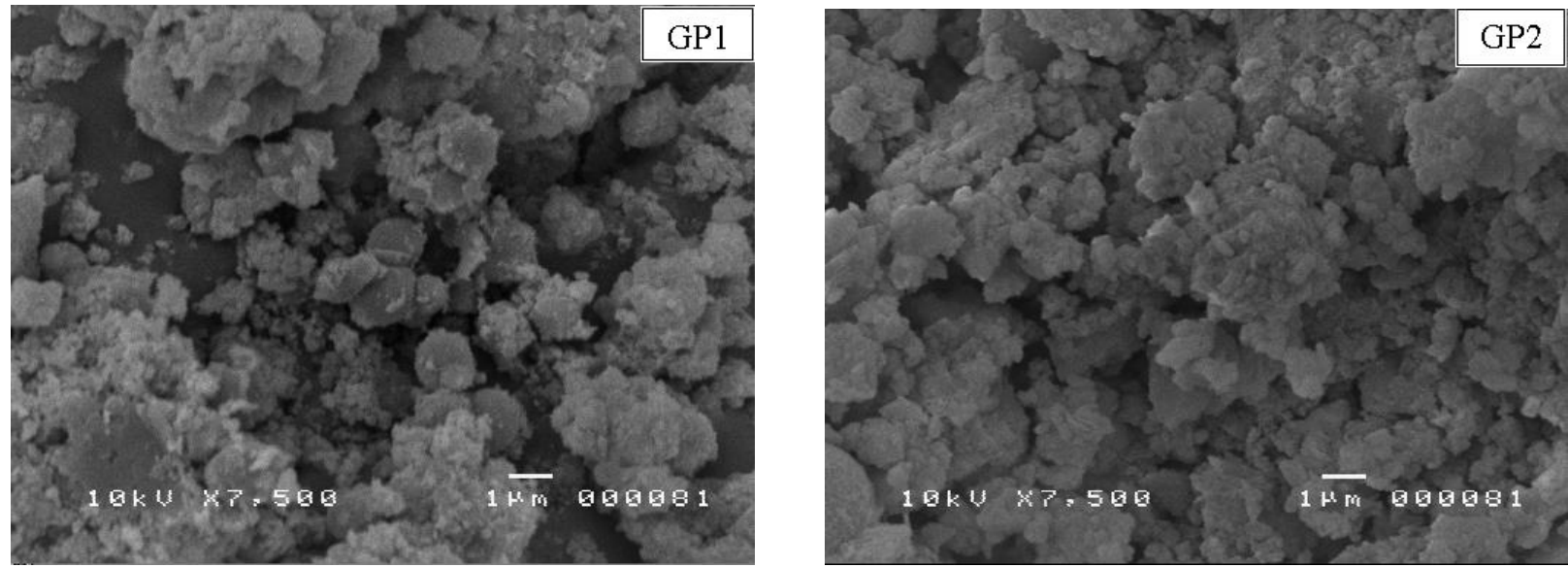

Fig. 4. SEM images of geopolymers GP1 and GP2

One-part geopolymer sample using sodium aluminate (GP2) has higher strength than the sample using WTS (GP1). It could be implied that WTS contains Al in inactive phases. Therefore, addition of WTS into the mixture could inhibit the reaction rate. Previous study explained that non-calcined sludge composed of colloidal $\mathrm{Al}(\mathrm{OH})_{3}$ which is the inert octahedral coordinated aluminium, particularly for geopolymer formation [12].

Geopolymer transformation was indicated by SEM micrographs in Figure 4. The microspheres typical for FA almost disappeared in the images of two specimens. Instead, SEM images present fine flakes and particles of ground product. This is associated with the attack of sodium hydroxide that weakened or destroyed the spheres.

\subsection{Durability against acid attack}

As presented in Table 3, one-part geopolymer binders are very durable with strong acidic environment. The strength values significantly increase after immersed in $5 \%$ sulphuric acid solution. After 28 days, sample GP2 gained additional $9 \mathrm{MPa}$ that is close to the increased strength of control samples. However, strength of GP1 slightly decreased. It indicates that utilization of sludge in one-part geopolymer inhibit the acid resistance

Table 3. Compressive strength and weight of samples before and after immersed in $5 \% \mathrm{H}_{2} \mathrm{SO}_{4}$ solution for 7 and $28 \mathrm{~d}$.

\begin{tabular}{lccccc}
\hline & & \multicolumn{2}{c}{ Acid immersed runs } & $\begin{array}{c}\text { Control } \\
\text { runs }\end{array}$ \\
\hline \multicolumn{2}{c}{ Duration (days) } & 0 & 7 & 28 & 28 \\
\hline $\begin{array}{l}\text { Strength } \\
(\mathrm{MPa})\end{array}$ & GP1 & 6.9 & 7.8 & 5.7 & 8.2 \\
& GP2 & 16.0 & 20.1 & 25.0 & 27.6 \\
$\begin{array}{l}\text { Weight } \\
(\text { wt.\%) }\end{array}$ & GP1 & 100 & 98.6 & 98.3 & 100 \\
\hline
\end{tabular}

capacity of product. Mass weights were nearly kept constant through the period of immersion. For both specimens, mass losses are smaller than $2 \%$.

\section{Conclusions}

Characterization of raw materials using XRF analysis indicated that FA and WTS have suitable elemental and mineral compositions for geopolymer synthesis. SEM micrograph presented that FA consists of spherical forms while WTS contains flaky glassy phases. Although, WTS has high over $\mathrm{Al}$ content $\left(30 \% \mathrm{Al}_{2} \mathrm{O}_{3}\right)$, utilization of this Al-source material in one-part geopolymer significantly reduced compressive strength.

One-part geopolymers have shown very high resistance against sulphuric acid attack. Compressive strength and weight of 28-day acid immersed samples were not significantly different with those of water immersed control runs.

\section{Acknowledgement}

The authors acknowledge the financial support of Japan International Cooperation Agency (JICA) through the AUN/SEED-Net scholarship.

\section{References}

1. J. Davidovits, Geopolymer 2002 Conference (2002)

2. C.D. Atis, E.B. Görür, O. Karahan, C. Bilim, S. Ilkentapar, E. Luga, Construction and Building Materials, 96, 673-678 (2015)

3. G. Habert, C. Billard, P. Rossi, C. Chen, N. Roussel, Cement and Concrete Research, 40, 820-826 (2010)

4. F. De Lillo, F. Cecconi, G. Lacorata, A. Vulpiani, EPL, 84 (2008)

5. H. Choo, S. Lim, W. Lee, C. Lee, Construction and Building Materials, 125, 21-28 (2016)

6. American Society for Testing Materials. Standard Test Method for Compressive Strength of Hydraulic 
Cement Mortars (Using 2-in. or [50-mm] Cube Specimens) (ASTM C109/109M - 16a). ASTM International, (2016)

7. American Society for Testing Materials. Standard Test Methods for Chemical Resistance of Mortars, Grouts, and Monolithic Surfacings and Polymer Concretes (ASTM C267-01). ASTM International, (2012)

8. S. Thokchom, P. Ghosh, S. Ghosh, ARPN Journal of Engineering and Applied Sciences, 4, 1 (2009)

9. V. Kannan, K. Ganesan, Construction and Building Materials, 51, 225-234 (2014)

10. T. Bakharev, Cement and Concrete Research, 35 , 658-670, (2005)

11. A.S. Vargas, D.C.C.D Molin, A.C.F. Vilela, F.J. Silva, B. Pavão, B., H. Veit, Cement \& Concrete Composites, 33, 653-660 (2011)

12. M.A. Tantawy, Materials Research Bulletin, 61, 415-421 (2014)

13. J. Davidovits, Geopolymer chemistry and application $\left(4^{\text {th }}\right.$ ed.). Institut Géopolymère - France (2011)

14. American Society for Testing Materials. Standard Specification for Nonloadbearing Concrete Masonry Units (ASTM C129-14a). ASTM International, (2015) 